\title{
Development of Biodegradable Delivery Systems Containing Novel 1,2,4-Trioxolane Based on Bacterial Polyhydroxyalkanoates
}

\author{
Sergei Y. Lipaikin $\left(\mathbb{D},{ }^{1}\right.$ Ivan A. Yaremenko ${ }^{(D)},{ }^{2}$ Alexander O. Terent'ev ${ }^{(D)}{ }^{2}$ \\ Tatiana G. Volova ${ }^{D},{ }^{1,3}$ and Ekaterina I. Shishatskaya ${ }^{1}$ \\ ${ }^{1}$ Siberian Federal University, 79 Svobodnyi av Krasnoyarsk, 660041, Russia \\ ${ }^{2}$ N.D. Zelinsky Institute of Organic Chemistry, Russian Academy of Sciences, 47 Leninsky Prosp Moscow, 119991, Russia \\ ${ }^{3}$ Institute of Biophysics SB RAS, 50/50 Akademgorodok, Krasnoyarsk 660036, Russia
}

Correspondence should be addressed to Sergei Y. Lipaikin; lipaikinsj@gmail.com

Received 14 December 2021; Revised 7 February 2022; Accepted 9 February 2022; Published 28 February 2022

Academic Editor: Chiara Gualandi

Copyright (c) 2022 Sergei Y. Lipaikin et al. This is an open access article distributed under the Creative Commons Attribution License, which permits unrestricted use, distribution, and reproduction in any medium, provided the original work is properly cited.

\begin{abstract}
In this work, delivery systems in the form of microparticles and films containing 1,2,4-trioxolane (ozonide, OZ) based on polyhydroxyalkanoates (PHAs) were developed. Main systems' characteristics were investigated: the particle yield, average diameter, zeta potential, surface morphology, loading capacity, and drug release profile of microparticles, as well as surface morphology and release profiles of OZ-containing films. PHA-based OZ-loaded microparticles have been found to have satisfactory size, zeta potential, and ozonide loading-release behavior. It was noted that OZ content influenced the surface morphology of obtained systems.
\end{abstract}

\section{Introduction}

Over the past decade, cyclic organic peroxides have been intensively researched by chemists and pharmacologists. The discovery of the natural peroxide artemisinin [1-3], which has antimalarial properties, was the beginning of the development of biologically active peroxides (Figure 1). It has been found that cyclic peroxides have antimalarial [4-12], antiparasitic [13-19], anticancer [20-31], antiviral [32-34], and fungicidal $[18,35,36]$ activities. On the basis of the fully synthetic peroxide arterolane, which contains a 1,2,4-trioxolane (ozonide) fragment, has been created an antimalarial drug of the latest generation-Synriam [37]. It was recently found that artesunate is able to inhibit NL63 $\alpha$-coronavirus and OC43 $\beta$-coronavirus, while ozonides OZ277 and OZ418 are able to inhibit both $\alpha$-coronavirus NL63, $\beta$-coronavirus OC43, and SARS-CoV-2 [38].

Controlled release drug delivery systems based on biodegradable polymeric films and microparticles can reduce detrimental side effects of biologically active substances. The matrix of such systems must be biocompatible, in the case of medical use, and environmentally safe and friendly, for use in agriculture.

Poly(lactic-co-glycolic acid) (PLGA) [39-41], polycaprolactone (PCL) [42, 43], and polyhydroxyalkanoates (PHAs) $[44,45]$ are widely used as a polymer matrix for depot systems. One of the most perspective matrices of such systems is PHAs, bacterial polyesters that possess biodegradability in biological media, biocompatibility, and nontoxicity. PHAs are water-insoluble semicrystalline substances suitable for medical, agricultural, and industrial applications [46-48].

Poly-3-hydroxybutyrate (P3HB) is the first well-described and studied microbial short-chain length polyhydroxyalkanoate (Figure 2(a)). The P3HB degree of crystallinity is about $72 \%$, the melting point is between 174 and $179^{\circ} \mathrm{C}$, and it also has a wide range of molecular weight distribution, depending on the cultivation procedure [49]. P3HB copolymers with poly-3-hydroxyvalerate, $\mathrm{P} 3 \mathrm{HV}$ ( $\mathrm{PHBV}$, the molar fraction of $\mathrm{P} 3 \mathrm{HV}$ varies from $10 \%$ to $80 \%$ ), are recognized as more elastic and plastic material, surpassing $\mathrm{P} 3 \mathrm{HB}$ in absolute strength and Young's modulus. These properties make PHBV more suitable in bioengineering, for obtaining particles, films, scaffolds, 
and surgical suture (maintaining high biocompatibility for different biological systems and complete biodegradation) [47]. Anti-inflammatory [50], antibacterial [51], antitumor [52], herbicidal [53], and other drugs have been successfully encapsulated in the PHA matrix.

The natural antimalarial drug artemisinin (ART) is the most commonly used substance in the development of peroxide-containing controlled release systems. Polymerbased systems for ART delivery are usually based on PLGA [54], PCL [55], and cyclodextrin [56].

As far as we know, there are no data in the literature about the encapsulation of synthetic peroxides into the PHA matrix. In this work, we have chosen the synthetic ozonide (OZ) as the model object. OZ (Figure 2(b)) is a hydrophobic white powder that dissolves in DMSO, chloroform, and acetonitrile. The absorption maxima of the substance are in the UV region (268 and $276.5 \mathrm{~nm}$ ). Since ozonides related to OZ exhibit anticancer [25-27], antiparasitic [57], and fungicidal activity [36], PHA-microparticles containing OZ might be potentially used for cancer treatment along with other known drug delivery systems based, for example, on lipid nanovesicles [58], leukocyte-mimicking nanovesicles [59], and immunoliposomes [60].

The aim of this research is to obtain OZ-containing depot systems based on P3HB and PHBV in the form of microparticles and casting films and to study their basic physical, chemical, and cytotoxic properties against HeLa cells.

\section{Material and Methods}

2.1. Material. Microbial P3HB was obtained by the fermentation process: $M_{\mathrm{w}}=1480 \mathrm{kDa}$ (for emulsification method), $M_{\mathrm{w}}=96 \mathrm{kDa}$ (for spray drying method), and PHBV polymer with molar ratio 90:10 (P3HB:P3HV) and $M_{\mathrm{w}}=260 \mathrm{kDa}$. Studied polymers and copolymer were produced at the laboratory of Biotechnology of new biomaterials of Siberian Federal University in Krasnoyarsk, RF. OZ was synthesized according to the procedure described in the literature in the Institute of Organic Chemistry, Russian Science Academy [61]. DMSO and PVA were purchased from SigmaAldrich (USA). All chemicals were used as received without any further purifications.

\subsection{Preparation of OZ-Loaded PHBV Films (OZ-F). PHBV} films containing $\mathrm{OZ}$ were prepared by the solution casting method. $250 \mathrm{mg}$ of PHBV was dissolved in chloroform under heating. After that, the solution of $\mathrm{OZ}$ in chloroform with a concentration of $1 \mathrm{mg} \mathrm{ml}^{-1}$ was added to obtain films containing 0.008 wt.\%, $0.016 \mathrm{wt} . \%$, and $0.024 \mathrm{wt} . \%$ of $\mathrm{OZ}$ $\left(23.5,47\right.$, and $70.5 \mu \mathrm{mol} \mathrm{g}^{-1}$, respectively). The resulting solution was transferred to a sterile Petri dish and left until complete solvent evaporation (at room temperature for $48 \mathrm{~h}$ ). As a control, PHBV-based films without $\mathrm{OZ}$ were obtained under similar conditions.

2.3. Preparation of OZ-Loaded P3HB Microparticles by Emulsification Method $\left(\mathrm{OZ}-M P_{E M}\right)$. OZ-MP $\mathrm{EM}_{\mathrm{EM}}$ were prepared using water in oil emulsion containing $0.4 \mathrm{~g}$ of $\mathrm{P} 3 \mathrm{HB}$,
$0.04 \mathrm{~g}$ of $\mathrm{OZ}$ in $40 \mathrm{ml}$ of dichloromethane (DCM), and $100 \mathrm{ml}$ of $0.5 \%$ aqueous PVA solution. The resulting emulsion was mechanically stirred at $5000 \mathrm{rpm}$ for $3 \mathrm{~min}$ (Heidolph SilentCrusher $\mathrm{M}$, Germany). After complete

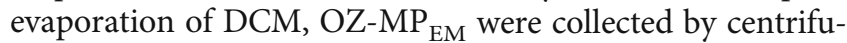
gation at $4000 \mathrm{rpm}$ for $3 \mathrm{~min}$, washed multiple times with deionized water, and then lyophilized.

Unloaded microparticles $\left(\mathrm{MP}_{\mathrm{EM}}\right)$ were obtained under similar conditions.

2.4. Preparation of OZ-Loaded P3HB Microparticles by Spray Drying Method (OZ-MPSD). The Büchi spray dryer (BUCHI Laboratory Equipment, Switzerland) OZ-MP $\mathrm{SD}_{\mathrm{SD}}$ was used for the spray drying of $\mathrm{P} 3 \mathrm{HB} / \mathrm{OZ}$ solution $(80 \mathrm{mg}$ of $\mathrm{P} 3 \mathrm{HB}$, $40 \mathrm{mg}$ of $\mathrm{OZ}$ dissolved in $80 \mathrm{ml}$ of DCM), with nitrogen as a drying gas, at a flow rate of $4.5 \mathrm{ml} \mathrm{min}^{-1}$.

Microparticles $\left(\mathrm{MP}_{\mathrm{SD}}\right)$ without $\mathrm{OZ}$ were obtained under similar conditions.

\subsection{Characterization of Films}

2.5.1. Morphological Analysis. The surface morphology analysis of films was carried out by scanning electron microscopy (SEM) using SU3500 and TM4100 (Hitachi, Japan). In order to determine the average roughness $(\mathrm{Sa})$ of the surface atomic force, microscopy (AFM) (Solver Nano, NTMDT, Russia) was used.

2.5.2. Determination of Surface Characteristics. Film surface characteristics towards liquids were measured using the Drop Shape Analyzer (KRÜSS, Germany) with distilled water as a polar liquid.

By measuring contact angles ( $\theta$, degrees) (water/air), free surface energy $\left(\gamma_{\mathrm{S}}\right)$, free interface energy $\left(\gamma_{\mathrm{SL}}\right)$, and cohesive force $\left(W_{\mathrm{SL}}\right)\left(\mathrm{erg} / \mathrm{cm}^{2}\right)$ were calculated.

Free surface energy of PHBV films was calculated according to the following equation:

$$
\gamma_{\mathrm{S}}=\frac{\gamma_{\mathrm{L}}(1+\cos \theta)^{2}}{4}
$$

where $\gamma_{\mathrm{L}}$ is free water surface tension, $72.8 \mathrm{erg} / \mathrm{cm}^{2}$.

Free interface energy (polymer/water) was found from the formula:

$$
\gamma_{\mathrm{SL}}=\gamma_{\mathrm{S}}+\gamma_{\mathrm{L}}-W_{\mathrm{SL}}
$$

The cohesive force was calculated from the formula

$$
W_{\mathrm{SL}} \approx 2 \sqrt{\gamma_{\mathrm{S}} \gamma_{\mathrm{L}}}
$$

\subsection{Characterization of Microparticles}

2.6.1. Morphological Analysis. The surface morphology analysis of polymer microparticles was carried out as above. A number of samples were sputter coated with platinum using Leica EM ACE200 (Leica Microsystems, Germany) to obtain a good-quality SEM image. 


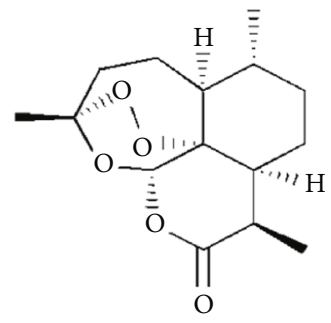

Artemisinin (ART)

$$
\text { antimalarial }
$$

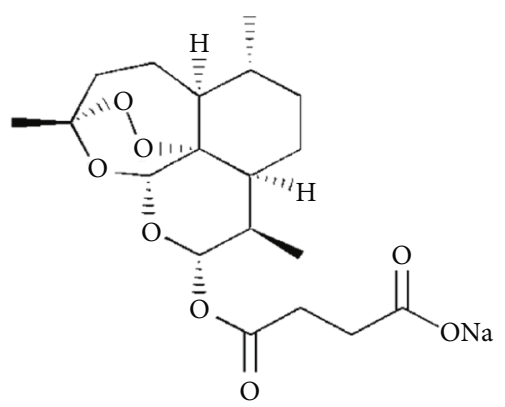

Artesunate antimalarial

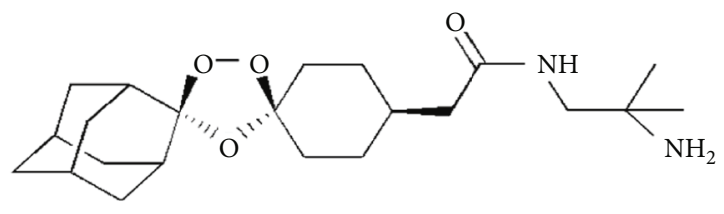

Artesunate (OZ277)

Synriam ${ }^{T M}$ antimalarial

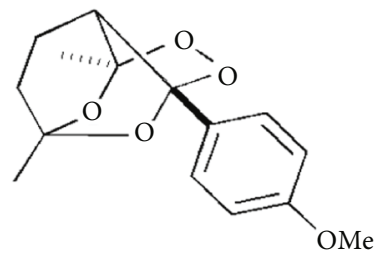

Tricyclic monoperoxide Anthelmintic

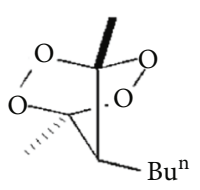

Bridged tetraoxane Antifungal

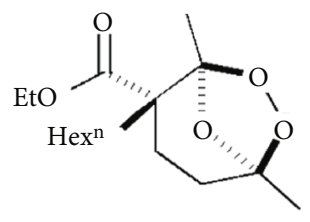

Bridged ozonide Anticancer

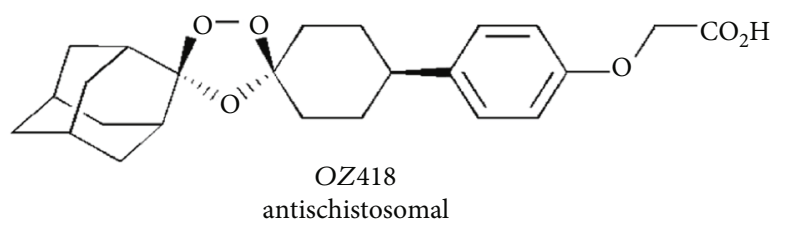

FIGURE 1: Biologically active peroxides of natural, semisynthetic, and synthetic origin.<smiles>CC(C)OCC(=O)O</smiles>

P3HB<smiles>CCOC(=O)[C@@]12CC[C@]3(C)OO[C@](C)(OO3)[C@]1(Cc1ccc(Cl)cc1)O2</smiles>

(b)

Figure 2: Structures of poly-3-hydroxybutyrate (P3HB) and OZ. 


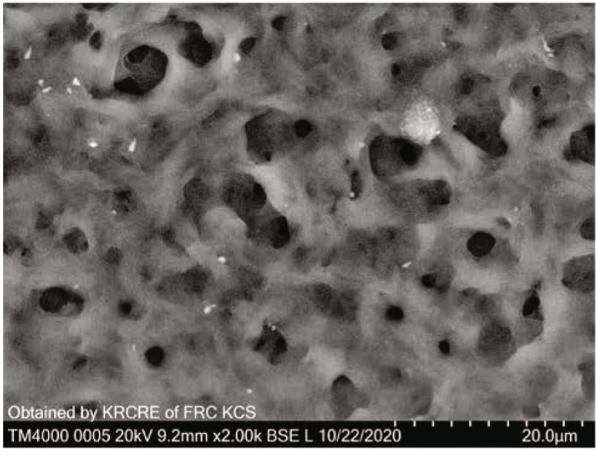

(a)

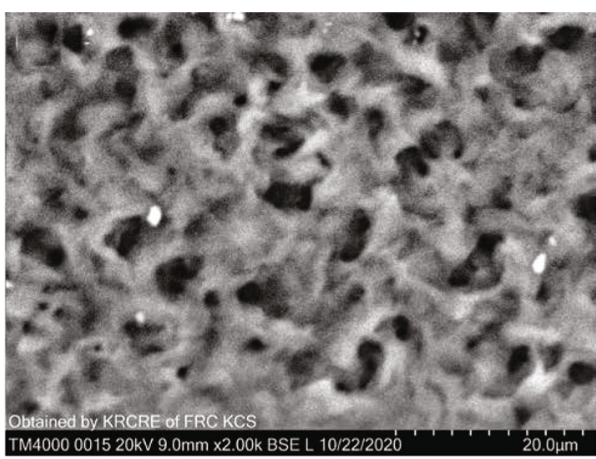

(c)

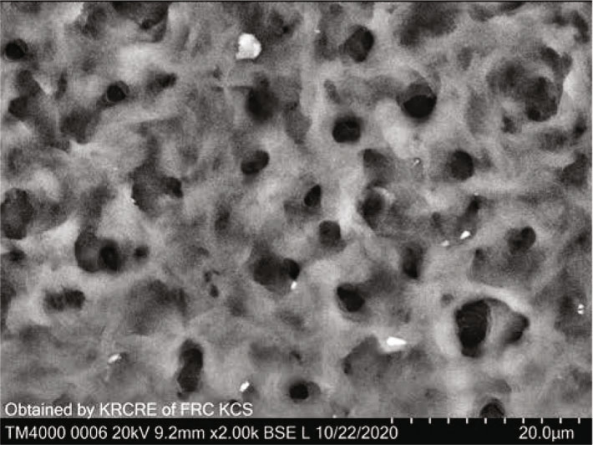

(b)

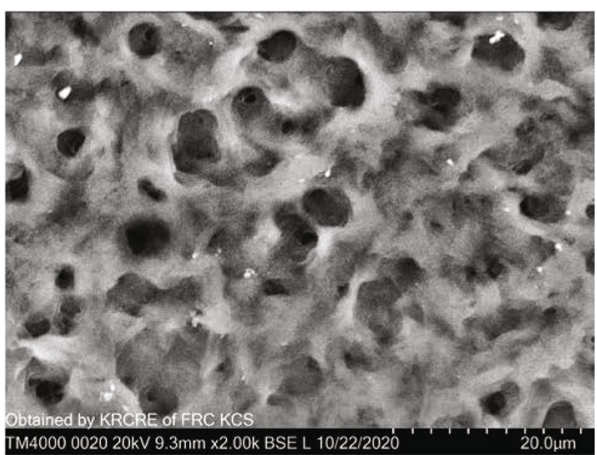

(d)

Figure 3: SEM (TM4100 (Hitachi, Japan)) images of PHBV and OZ-PHBV films. (a) PHBV-F; (b) OZ-F, 0.008\% of OZ; (c) OZ-F, 0.016\% of OZ; (d) OZ-F, $0.024 \%$ of OZ.

2.6.2. Total Yield of Microparticles. Total yields of microparticles (\%) were determined according to

$$
\operatorname{Yield}(\%)=\frac{M_{m}}{M_{p}} \cdot 100,
$$

where $M_{m}$ is the mass of microparticles and $M_{p}$ is the initial mass of $\mathrm{P} 3 \mathrm{HB}$, used in synthesis.

2.6.3. Particle Size and Zeta Potential. Zetasizer Nano ZS (Malvern, UK) was used to determine the average particle size, zeta potential, particle size distribution (PSD), and polydispersity index (PDI). $5 \mathrm{mg}$ of each sample was suspended in deionized water and sonicated at $6 \mathrm{~W}$ for $1 \mathrm{~min}$ before the measurements.

2.6.4. DSC Analysis. Differential scanning calorimetry, DSC, analysis was carried out to determine the melting behavior of $\mathrm{MP}_{\mathrm{EM}}$ and OZ-MP $\mathrm{EM}_{\mathrm{EM}}$ using Mettler Toledo STAR DSC 1 (USA), samples were heated at a rate of $10^{\circ} \mathrm{C} \mathrm{min}^{-1}$, and the data were recorded from 20 to $300^{\circ} \mathrm{C}$.

2.6.5. Drug Encapsulation Efficiency (for Microparticles) and In Vitro OZ Efflux. The amount of OZ encapsulated in the P3HB microparticles was determined spectrophotometrically using Genesys 10S UV-Vis (Thermo Scientific, USA). Firstly, $\mathrm{MP}_{\mathrm{EM}}$ and $\mathrm{MP}_{\mathrm{SD}}$ containing $\mathrm{OZ}$ were dissolved in DCM. Then, the absorbance (at $268 \mathrm{~nm}$ ) of each solution was measured, and a calibration curve (pure OZ in DCM) was plotted. The amount of OZ in MPs was determined using the standard curve.

The encapsulation efficiency (EE) was determined according to the formula

$$
\mathrm{EE}(\%)=\frac{M_{1}}{M_{2}} \cdot 100,
$$

where $M_{1}$ is the mass of $\mathrm{OZ}$ in microparticles and $M_{2}$ is the initial mass of OZ.

The investigation of the release of OZ from OZ-MPs was carried out in vitro. Samples of the studied microparticles were placed in sterile centrifuge tubes containing DMSO ( $2 \mathrm{mg}$ MPs in $1 \mathrm{ml}$ DMSO). Tubes were thermostated at $37^{\circ} \mathrm{C}$, with the microparticles precipitated by centrifugation, $11000 \mathrm{rpm}, 5 \mathrm{~min}$, at predetermined time intervals. The amount of OZ released was determined by the measurement of absorbance of the supernatant at $268 \mathrm{~nm}$.

To assess the release profile of $\mathrm{OZ}$ from OZ-containing films, each film was cut in circles with a diameter of $6 \mathrm{~mm}$. Then, the circles were placed in sterile tubes containing DMSO, and the amount of OZ released during 9 days was measured as mentioned above.

2.7. Cell Culture. HeLa cells, as a model adhesive culture for the estimation of cytotoxic effect, were cultured in Gibco Dulbecco's modified Eagle's medium (DMEM, Thermo Fisher Scientific, USA) with the addition of fetal bovine serum (HyClone, USA) and standard antibiotic-antimycotic supplement (Sigma-Aldrich, USA). 3-(4,5-Dimethylthiazol- 
TABLE 1: Characteristics of PHBV and OZ-F.

\begin{tabular}{|c|c|c|c|c|}
\hline \multirow[b]{2}{*}{ Parameter } & \multicolumn{4}{|c|}{ Concentration of OZ in PHBV film } \\
\hline & $\begin{array}{c}0(\text { wt. } \%) \\
0\left(\mu \mathrm{mol} \mathrm{g}^{-1}\right)\end{array}$ & $\begin{array}{c}0.008(\text { wt.\%) } \\
23.5\left(\mu \mathrm{mol} \mathrm{g}^{-1}\right)\end{array}$ & $\begin{array}{l}0.016(\mathrm{wt} . \%) \\
47\left(\mu \mathrm{mol} \mathrm{g}^{-1}\right)\end{array}$ & $\begin{array}{c}0.024(\text { wt. \%) } \\
70.5\left(\mu \mathrm{mol} \mathrm{g}^{-1}\right)\end{array}$ \\
\hline Average roughness $(\mathrm{nm})$ & $311.0 \pm 0.3$ & $189.7 \pm 0.2$ & $413.1 \pm 0.3$ & $664.2 \pm 0.1$ \\
\hline Contact angle for water in air $(\theta$, degrees) & $62.3 \pm 1.56$ & $92.5 \pm 1.49$ & $78.0 \pm 1.54$ & $79.8 \pm 1.52$ \\
\hline Free surface energy $\gamma_{\mathrm{S}}\left(\mathrm{erg} / \mathrm{cm}^{2}\right)$ & $39.05 \pm 0.25$ & $42.4 \pm 0.49$ & $48.0 \pm 0.71$ & $42.7 \pm 0.67$ \\
\hline Free interface energy $\gamma_{\mathrm{SL}}\left(\mathrm{erg} / \mathrm{cm}^{2}\right)$ & $5.21 \pm 0.18$ & $4.08 \pm 0.16$ & $2.57 \pm 0.19$ & $3.99 \pm 0.20$ \\
\hline Cohesive forces $\left(\mathrm{erg} / \mathrm{cm}^{2}\right)$ & $106.64 \pm 1.36$ & $111.11 \pm 1.29$ & $118.22 \pm 1.33$ & $111.50 \pm 1.37$ \\
\hline
\end{tabular}

TABLe 2: Parameters of the obtained microparticles.

\begin{tabular}{lccccc}
\hline Sample & Yield $(\%)$ & Average diameter $(\mu \mathrm{m})$ & PDI & Zeta potential $(\mathrm{mV})$ & Encapsulation efficiency $(\%)$ \\
\hline $\mathrm{MP}_{\mathrm{EM}}$ & $89.2 \pm 0.3$ & $0.35 \pm 0.02$ & $0.132 \pm 0.011$ & $-23.8 \pm 0.2$ & - \\
$\mathrm{MP}_{\mathrm{SD}}$ & $31.1 \pm 0.3$ & $2.1 \pm 0.1$ & $0.121 \pm 0.014$ & $-45.2 \pm 0.2$ & - \\
$\mathrm{OZ}-\mathrm{MP}_{\mathrm{EM}}$ & $92.4 \pm 0.2$ & $0.44 \pm 0.03$ & $0.182 \pm 0.012$ & $-13.8 \pm 0.3$ & $89.4 \pm 0.2$ \\
OZ-MP $_{\mathrm{SD}}$ & $26.6 \pm 0.4$ & $2.6 \pm 0.1$ & $0.149 \pm 0.022$ & $-39.6 \pm 0.4$ & $37.7 \pm 0.3$ \\
\hline
\end{tabular}

2-yl)-2,5-diphenyltetrazolium bromide (MTT) technique was used to evaluate the cytotoxic activity of the obtained depot systems.

For the MTT study, the cell suspension was incubated with the studied systems for 24 hours. Then, MTT (in PBS buffer) was added to all samples; the cell culture plate was then incubated at $37^{\circ} \mathrm{C}$ for $4 \mathrm{~h}$. The resulting formazan was dissolved in DMSO, and the absorbance was determined at $550 \mathrm{~nm}$ using an iMark Microplate Reader (Bio-Rad Laboratories, USA).

Cell viability (\%) was calculated according to the equation below:

$$
\text { Cell viability }(\%)=\frac{[A] \text { test }}{[A] \text { control }} \cdot 100 \text {, }
$$

where $[A]$ test is the absorbance of the test sample and $[A]$ control is the absorbance of the control sample.

The Trypan blue assay was used to assess cell death as a result of interaction with depot systems. After coincubation for 24 hours, cells were harvested using 0.25\% TrypsinEDTA (Gibco, USA) and centrifuged; the supernatant was removed and resuspended in DMEM. Trypan blue solution (Gibco, USA) was added to the cell suspension, which was layered on a microscope slide.

The number of living cells was determined in the hemocytometer using the following formula:

$$
X=N \cdot 0.05 \cdot 10^{m} \cdot m,
$$

where $X$ is the number of cells in $1 \mathrm{ml}, N$ is the number of cells in 5 large squares, and $m$ is dilution.

Four replicates were performed for each sample.

To visualize cell viability during interaction with the studied systems, a LIVE/DEAD assay was performed using a ReadyProbes ${ }^{\mathrm{TM}}$ double staining kit (Thermo Fisher, USA) in accordance with the manufacturer's protocol. Images were obtained using the Leica digital microscope (Leica Microsystems $\mathrm{GmbH}$, Germany). Live and dead cells had blue and green fluorescence, respectively. Images were analyzed using NIH ImageJ software.

\section{Results and Discussion}

In this work, for the first time, two OZ-loaded depot systems based on PHA were developed. The systems obtained were sufficiently stable in model medium and had high drug loading and encapsulation efficiency. We were not absolutely sure about the successful encapsulation of organic peroxides into the PHA matrix, since the interaction of the carboxyl groups of PHAs with peroxides can lead to the decomposition of the peroxide or its rearrangements, such as the rearrangements of Baeyer-Villiger, Criegee, Hock, etc. [62]. According to the obtained absorption spectra of pure $\mathrm{OZ}$ and PHAs before and after the encapsulation procedure (not shown), there were no changes noted in the structure of the peaks and their position in the spectra, which was an indication of the absence of any rearrangements or decomposition of molecules.

PHAs have undeniable advantages as a matrix for depot systems, compared to PLGA and other hydrophilic polymers. PHAs are almost inert to hydrolysis and only biodegrade under enzymatic processes in aerobic conditions, without local shifts in the $\mathrm{pH}$ of the biological system to the acidic region, as in the case of PLGA. In this work, we studied the release of OZ from microparticles and films containing $7.1 \% \quad\left(\mathrm{OZ}-\mathrm{MP}_{\mathrm{SD}}\right), \quad 9.7 \%\left(\mathrm{OZ}-\mathrm{MP}_{\mathrm{EM}}\right), \quad 0.008 \%$, $0.016 \%$, and $0.024 \%$ of OZ (wt. $\%$ ).

3.1. Characterization of Films. For the estimation of the applicability of the approach, we obtained casting films by combining chloroform solutions of two components of the depot system. Resulted films had relatively homogeneous 


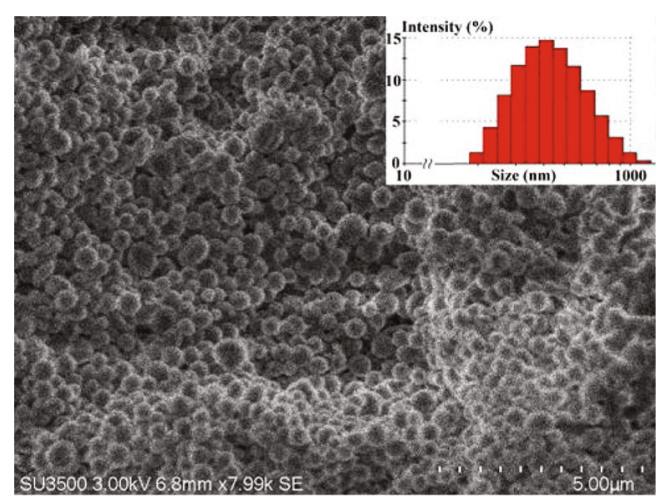

(a)

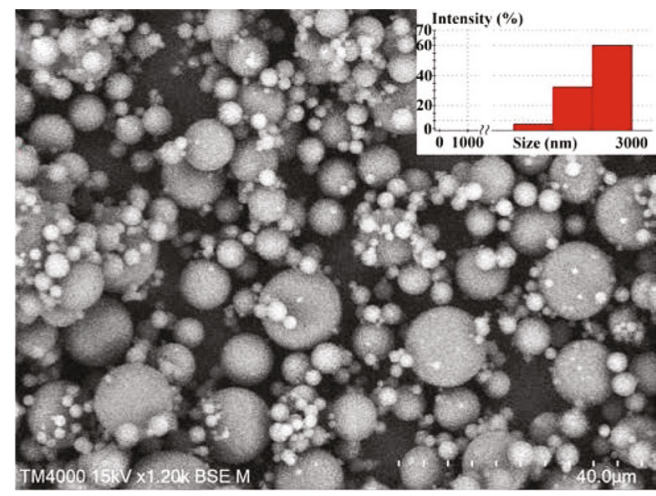

(c)

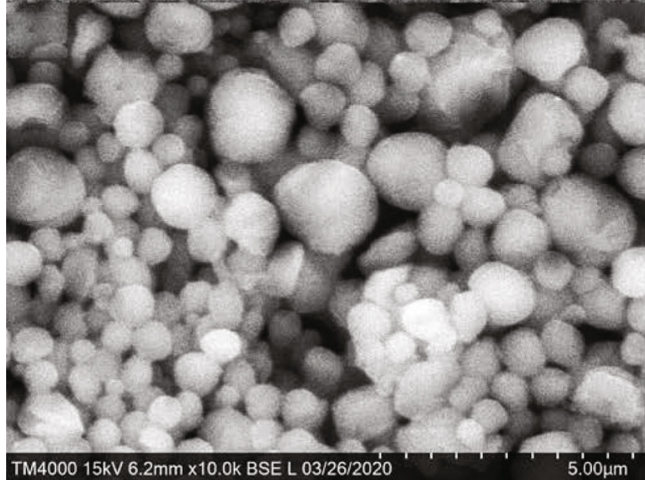

(b)

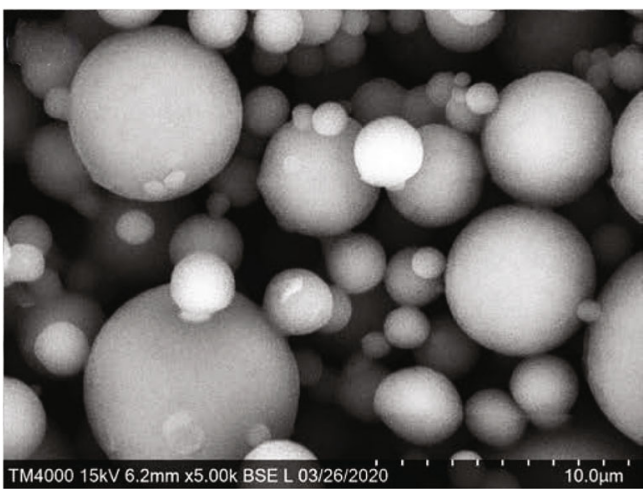

(d)

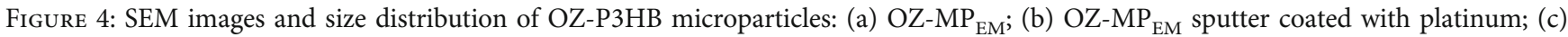
$\mathrm{OZ}_{\mathrm{MP}}$; (d) OZ-MP $\mathrm{SD}_{\mathrm{S}}$ sputter coated with platinum.

structures. The surface of OZ-F was rough and porous, with pore sizes ranging from 0.5 to $6 \mu \mathrm{m}$ (Figure 3 ).

As a result of the addition of $\mathrm{OZ}$ to the PHA, we detected the increasing of the porosity and average roughness of the sample surface, compared with the control, with both microscopy approaches-SEM and AFM. Increasing the ozonide concentration in the film leads to a linear increasing in the average surface roughness (Table 1).

The films' surface characteristics are presented in Table 1.

Since OZ is encapsulated into the PHBV matrix, all the studied parameters of the obtained films significantly change. When the amount of $\mathrm{OZ}$ in the film increases from $0 \%$ to $0.008 \%$, the contact angle (water in air) increases by more than $30 \%$ : from $62.3 \pm 1.56$ to $92.5 \pm 1.49$ degrees, so the resulted film surface becomes more hydrophobic. The free surface energy reaches its maximum at $0.016 \%$ of $\mathrm{OZ}$ in PHBV film, $48.0 \pm 0.71 \mathrm{erg} / \mathrm{cm}^{2}$; the presence of $\mathrm{OZ}$ reduces the free interface energy of the $\mathrm{PHBV}-\mathrm{OZ}$ composite film. The cohesion forces are also increased, when $\mathrm{OZ}$ is added, by about $5-11 \%$.

Thus, with an increase of the ozonide concentration in the PHBV film, both its morphological, average roughness, and physical characteristics: water contact angle and free surface energy, free interface energy, and cohesion forces change. These results make it possible to predict the properties of these depot systems related to biological objects-water-containing medium, tissues, and cells. An increasing of cohesive forces can be regarded as a positive factor contributing to the tight attachment of cellular elements.

3.2. Characterization of Microparticles. OZ-MP have a uniform spherical shape. OZ-MP $\mathrm{SD}_{\mathrm{S}}$ were found larger and smoother than OZ-MP $\mathrm{EM}_{\text {. It was also noted that OZ-MP }}$ (Figure 4(b)) have minor surface defects.

The encapsulation of OZ into microparticles leads to the insignificant increasing in particle size: the average diameter of OZ-MP $\mathrm{EM}_{\mathrm{EM}}$ and OZ-MP $\mathrm{SD}_{\mathrm{SD}}$ was $0.440 .03 \mu \mathrm{m}$ and $2.6 \pm$ $0.1 \mu \mathrm{m}$, respectively, while the average diameter of $\mathrm{MP}_{\mathrm{EM}}$ was $0.35 \pm 0.02 \mu \mathrm{m}$ and the average size of $\mathrm{MP}_{\mathrm{SD}}$ was 2.1 $\pm 0.1 \mu \mathrm{m}$.

The results also indicate that $\zeta$-potential markedly decreases when OZ is encapsulated into both types of microparticles. The value of zeta potential of OZ-MP was -13.8 \pm 0.3 for $\mathrm{EM}$ and $-39.6 \pm 0.4 \mathrm{mV}$ for $\mathrm{SD}$, respectively (Table 2). The zeta potential of $\mathrm{MP}_{\mathrm{EM}}$ was $-23.8 \pm 0.2$ and $-45.2 \pm 0.2 \mathrm{mV}$ for $\mathrm{MP}_{\mathrm{SD}}$. In general, the morphology, size, and zeta potential of the microparticles obtained in this research are typical for PHA-based depot systems. Thus, encapsulation of ceftriaxone into the $\mathrm{P} 3 \mathrm{HB}$ matrix (Murueva et al. [63]) also leads to increasing the microparticle size.

The size of microparticles was $0.89 \pm 0.02 \mu \mathrm{m}$ for EM and $4.2 \pm 0.7 \mu \mathrm{m}$ for SD, compared to $0.74 \pm 0.02 \mu \mathrm{m}$ (EM) and $6.51 \pm 0.47 \mu \mathrm{m}$ (SD) for empty particles obtained under 


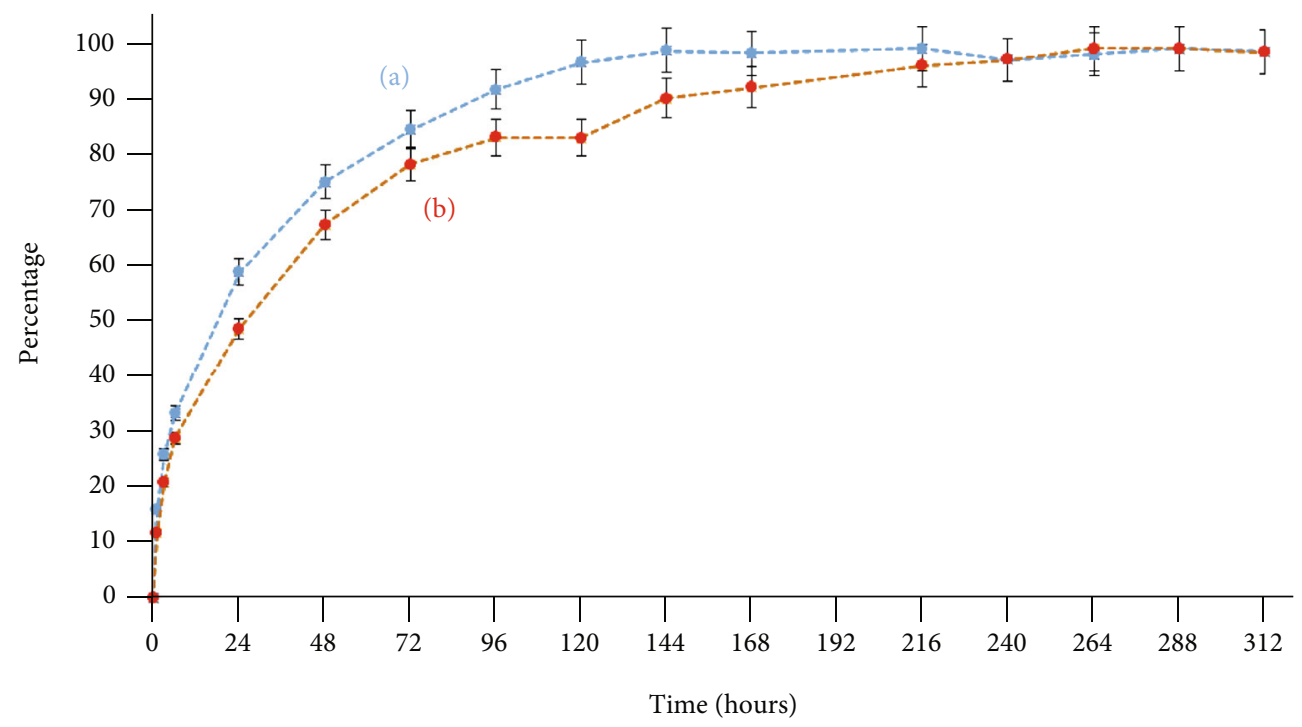

FIGURE 5: Release profiles (kinetic curves) of OZ-MP: (a) OZ-MP $\mathrm{EM}_{\text {; }}$ (b) OZ-MP $\mathrm{SD}_{\text {. }}$

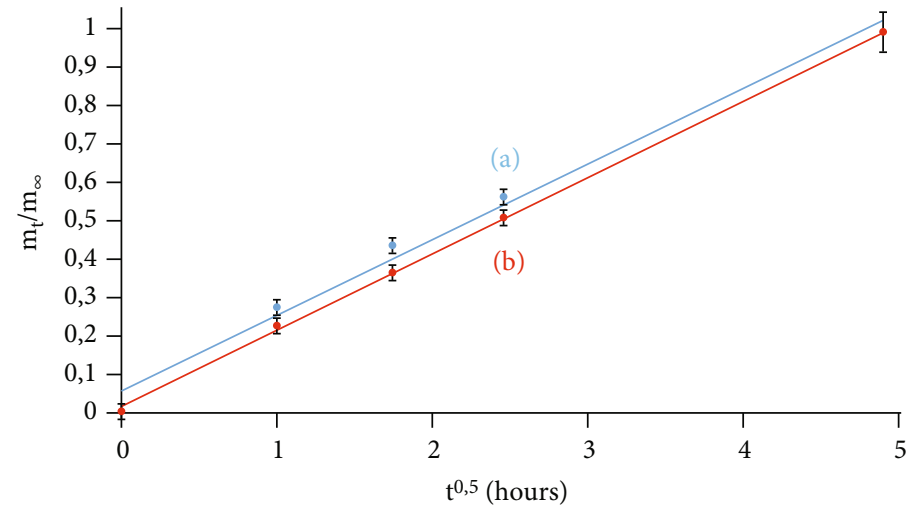

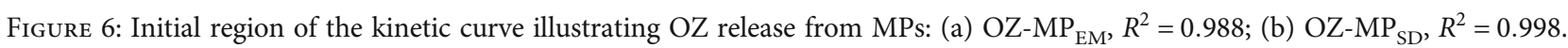

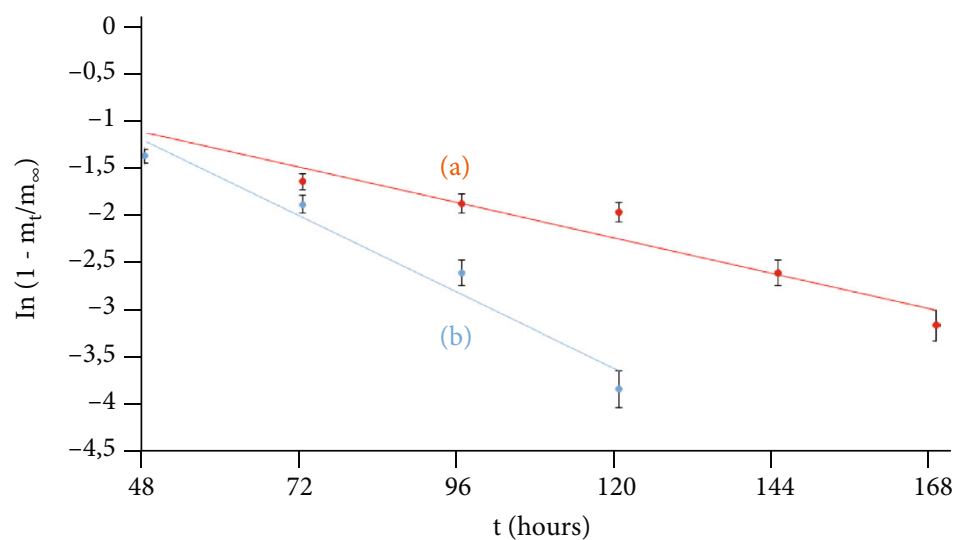

FIGURE 7: Final region of the kinetic curve illustrating OZ release from MPs: (a) $\mathrm{OZ}-\mathrm{MP}_{\mathrm{EM}}, R^{2}=0.960$; (b) $\mathrm{OZ}-\mathrm{MP}_{\mathrm{SD}}, R^{2}=-0.927$. 


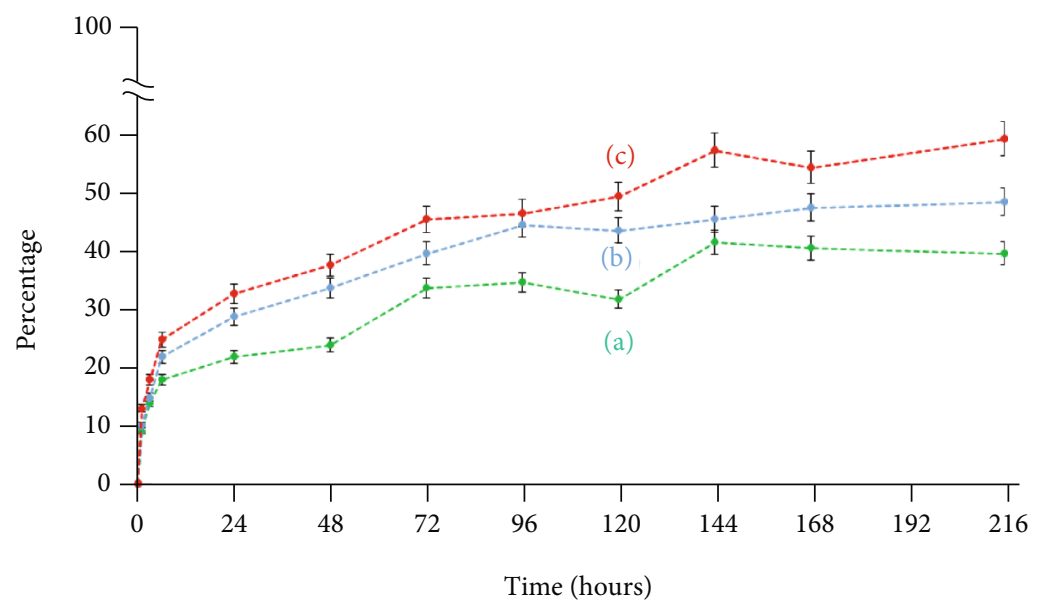

Figure 8: Release profiles (kinetic curves) of OZ-F: (a) OZ-F, $0.008 \%$ of OZ; (b) OZ-F, $0.016 \%$ of OZ; (c) OZ-F, $0.024 \%$ of OZ.

TABLe 3: The cell viability (films).

\begin{tabular}{lcccc}
\hline Sample & $\begin{array}{c}\text { OZ } \\
\text { concentration } \\
\text { in OZ-F } \\
(\text { wt.\% })\end{array}$ & $\begin{array}{c}\text { OZ } \\
\text { concentration } \\
\text { in OZ-F } \\
\left(\mu \mathrm{mol} \mathrm{g}^{-1}\right)\end{array}$ & $\begin{array}{c}\text { Cell } \\
\text { viability } \\
(\%)\end{array}$ & $\begin{array}{c}\text { The number } \\
\text { of cells·10 } \\
\left(\mathrm{cm}^{-2}\right)\end{array}$ \\
\hline 1 & 0 & 0 & $92.4 \pm 2.1$ & $35.9 \pm 1.2$ \\
2 & 0.008 & 23.5 & $21.2 \pm 1.1$ & $7.9 \pm 0.9$ \\
3 & 0.016 & 47 & $8.1 \pm 0.3$ & $3.1 \pm 0.5$ \\
4 & 0.024 & 70.5 & $2.1 \pm 0.2$ & $0.6 \pm 0.2$ \\
\hline
\end{tabular}

similar conditions. Zeta potential for ceftriaxone-loaded $\mathrm{MP}_{\mathrm{EM}}$ and $\mathrm{MP}_{\mathrm{SD}}$ was $-22.3 \pm 0.6 \mathrm{mV}$ and $-48.0 \pm 1.4 \mathrm{mV}$, respectively (compared to $-17.8 \pm 0.3 \mathrm{mV}$ and $-95.7 \pm 0.6$ $\mathrm{mV}$ for unloaded microspheres). Shershneva et al. [52] reported that the average diameter of $\mathrm{P} 3 \mathrm{HB}-\mathrm{MP}_{\mathrm{SD}}$ containing paclitaxel was $3.08 \pm 0.7 \mu \mathrm{m}$, and zeta potential was $40.8 \pm 0.9 \mathrm{mV}$, which is slightly lower than the same parameters of blank $\mathrm{P} 3 \mathrm{HB}-\mathrm{MP}_{\mathrm{SD}}$ : the average diameter was 3.36 $\pm 0.46 \mu \mathrm{m}$, and zeta potential was $-44.6 \pm 0.4 \mathrm{mV}$.

The yield of microparticles was excellent for OZ-MP $\mathrm{EM}_{\text {, }}$

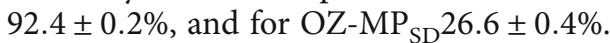

The encapsulation efficiency of $\mathrm{OZ}$ was $89.4 \pm 0.2 \%$ and $37.7 \pm 0.3 \%$ in $\mathrm{MP}_{\mathrm{EM}}$ and $\mathrm{MP}_{\mathrm{SD}}$, respectively. $\mathrm{EE}$ of $\mathrm{MP}_{\mathrm{SD}}$ is expectedly lower compared to $\mathrm{EE}$ of $\mathrm{MP}_{\mathrm{EM}}$. It can be explained by the peculiarities of the spray drying method [63].

3.2.1. Thermal Characteristics. According to the DSC results, OZ-MP $\mathrm{EM}_{\mathrm{E}}$ have a lower melting point $\left(T_{\mathrm{m}}=161.3^{\circ} \mathrm{C}\right)$ and crystallization temperature $\left(117.4^{\circ} \mathrm{C}\right)$ compared to $\mathrm{MP}_{\mathrm{EM}}$ $\left(176^{\circ} \mathrm{C}\right.$ and $123.6^{\circ} \mathrm{C}$, respectively). This is consistent with the results of Senhorini et al. [64], who noted a decrease in $T_{\mathrm{m}}$ of PHBV $(8.7 \%$ of $\mathrm{P} 3 \mathrm{HB}) \mathrm{MP}$ after encapsulation of andiroba oil, which has anti-inflammatory and insecticidal properties. Bidone et al. [65] and Volova et al. [66] reported that there is also a decrease in the melting point of polymer compositions based on $\mathrm{P} 3 \mathrm{HB}$ containing ibuprofen (by $10^{\circ} \mathrm{C}$ ) and metribuzin (by $2^{\circ} \mathrm{C}$ ), respectively.
As a result, OZ provides greater fusibility of the microparticle-based depot system, which can potentially lead to faster biodegradation.

3.2.2. OZ Release from MPs and Fs In Vitro. OZ release profiles from $\mathrm{MP}_{\mathrm{EM}}$ and $\mathrm{MP}_{\mathrm{SD}}$ are presented in Figure 5.

A significant drug release- $60 \%$ for $\mathrm{OZ}-\mathrm{MP}_{\mathrm{EM}}$ and $48 \%$ for $\mathrm{OZ}-\mathrm{MP}_{\mathrm{SD}}$-is achieved in 24 hours, and the full release of $\mathrm{OZ}$ occurs in 144 and 216 hours, respectively.

It was found that the $\mathrm{OZ}$ release from OZ-MP $\mathrm{EM}_{\mathrm{E}}$ and $\mathrm{OZ}-\mathrm{MP}_{\mathrm{SD}}$ depends on the sizes of microparticles and their surface structure having defects as pores and microcracks. OZ-MP $\mathrm{SD}_{\mathrm{SD}}$ have a smoother surface and larger sizes compared to $\mathrm{OZ}-\mathrm{MP}_{\mathrm{EM}}$, so the release rate from these microparticles is slower.

Each kinetic curve is characterized by two regions: the linear $(0-24 \mathrm{~h})$ and nonlinear $(48-312 \mathrm{~h})$ stages of $\mathrm{OZ}$ release from microparticles. To determine the drug release mechanism according to the Higuchi model, the diffusion coefficients were calculated at each of these regions.

In case of a short desorption time of $\mathrm{OZ}$ at the initial stage, Fick's second law (according to Higuchi model [67]) can be written as follows:

$$
\frac{m_{t}}{m_{\infty}}=4 \sqrt{\frac{D t}{\pi h^{2}}} n p u \frac{m_{t}}{m_{\infty}} \leq 0.6 \text {, }
$$

where $m_{t}$ is the mass of $\mathrm{OZ}$ desorbed at time $t, m_{\infty}$ is the mass of OZ desorbed at an infinite time $(t \longrightarrow \infty)$, and $h$ is matrix thickness.

Since the MP has a spherical shape, the matrix thickness $(h)$ is replaced by the particle diameter $(d)$. After linearization of the previous equation,

$$
\frac{m_{t}}{m_{\infty}}=4 \sqrt{\frac{D_{1} t}{\pi d^{2}}}
$$

The graphical solution of Equation (9) (Figure 6) allows us to determine the diffusion coefficient of $\mathrm{OZ}$ at the initial 
TABLe 4: The cell viability (microparticles).

\begin{tabular}{|c|c|c|c|c|}
\hline Sample & $\begin{array}{l}\text { OZ concentration in PHA } \\
(\text { wt. } \%)^{\mathrm{a}}\end{array}$ & OZ concentration in solution $\left(\mathrm{mmoll}^{-}\right.$ & $\begin{array}{l}\text { Cell viability } \\
(\%)\end{array}$ & $\begin{array}{c}\text { The number of cells } 10^{3}(\mathrm{~cm} \\
\left.{ }_{2}\right)\end{array}$ \\
\hline $\mathrm{MP}_{\mathrm{EM}}$ & & & $90.4 \pm 2.3$ & $33.6 \pm 1.4$ \\
\hline $\mathrm{MP}_{\mathrm{SD}}$ & & & $88.1 \pm 3.1$ & $31.9 \pm 1.1$ \\
\hline $\begin{array}{l}\mathrm{OZ} \\
\text { suspension }\end{array}$ & - & & $2.6 \pm 0.2$ & $0.8 \pm 0.2$ \\
\hline $\mathrm{OZ}-\mathrm{MP}_{\mathrm{EM}}$ & $9.7 \%$ & 10 & $10.6 \pm 1.4$ & $3.8 \pm 0.7$ \\
\hline OZ-MP ${ }_{\mathrm{SD}}$ & $7.1 \%$ & & $11.8 \pm 0.8$ & $4.3 \pm 0.2$ \\
\hline
\end{tabular}

${ }^{\mathrm{a} C a l c u l a t e d}$ concentration of $\mathrm{OZ}$ in particles (drug loading).

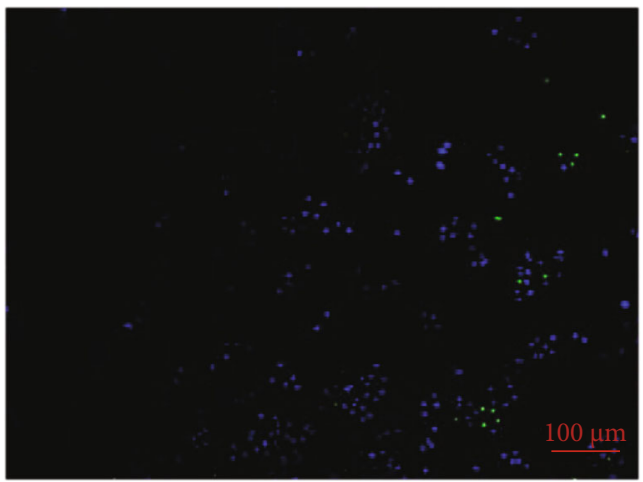

(a)

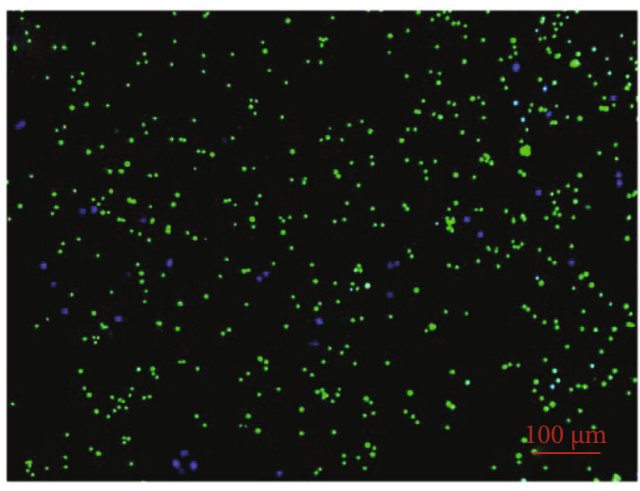

(c)

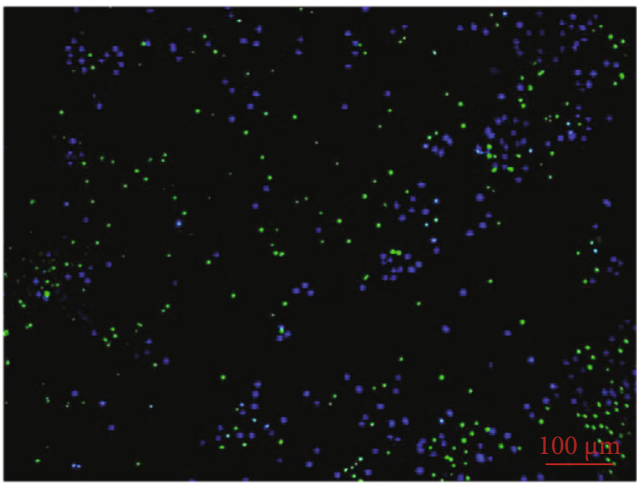

(b)

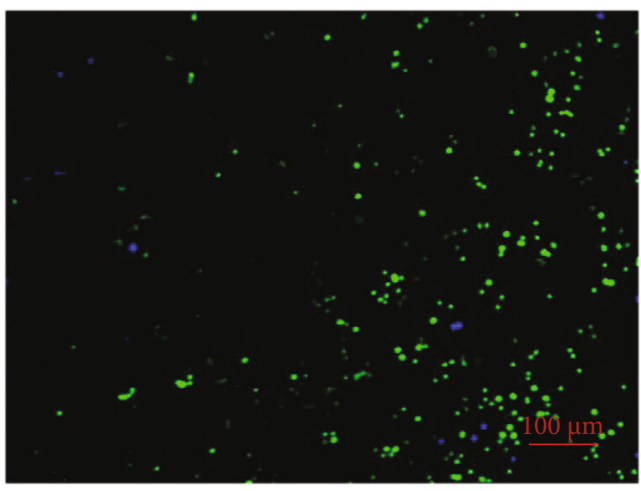

(d)

Figure 9: LIVE/DEAD assay for films: (a) PHBV film; (b) OZ-F, 0.008\% of OZ; (c) OZ-F, 0.016\% of OZ; (d) OZ-F, 0.024\% of OZ. Blue = live cells; green $=$ dead cells.

stage of the kinetic curve $\left(D_{1}\right) . D_{1}$ is equal to $6.1 \cdot 10^{-11} \mathrm{~cm}^{2} / \mathrm{s}$ for $\mathrm{OZ}-\mathrm{MP}_{\mathrm{EM}}$ and $2.2 \cdot 10^{-9} \mathrm{~cm}^{2} / \mathrm{s}$ for $\mathrm{OZ}-\mathrm{MP}_{\mathrm{SD}}$.

To determine the diffusion coefficient at the second stage $\left(D_{2}\right)\left(0.4 \leq m_{t} / m_{\infty} \leq 1.0\right)$, the following approximation is used:

$$
\frac{m_{t}}{m_{\infty}}=1-\left(\frac{8}{\pi^{2}}\right) e^{-D_{2} t \pi^{2} / d^{2}}
$$

The graphical solution of Equation (10) in semilog coordinates $\left(\ln \left[1-m_{t} / m_{\infty}\right]-t\right)$ (Figure 7 ) allows us to calculate $\mathrm{D}_{2}$ :

$$
D_{2}=\frac{\operatorname{tg} \alpha \cdot d^{2}}{\pi^{2}}
$$

$D_{2}$ for OZ-MP $\mathrm{EM}_{\mathrm{EM}}$ is $2.7 \cdot 10^{-11} \mathrm{~cm}^{2} / \mathrm{s}$ and for $\mathrm{OZ}-\mathrm{MP}_{\mathrm{SD}}$ is $0.5 \cdot 10^{-9} \mathrm{~cm}^{2} / \mathrm{s}$.

A significant decrease of $D_{2}$ for both types of microparticles indicates that the release mechanism of $\mathrm{OZ}$ changes.

Livshits et al. [68] obtained similar diffusion coefficients for microparticles of different sizes. For particles with an average size of $0.4 \mu \mathrm{m}$, the diffusion coefficients of dipyridamole into the release medium were $0.1 \cdot 10^{-11} \mathrm{~cm}^{2} / \mathrm{s}\left(D_{1}\right)$ and $0.08 \cdot 10^{-11} \mathrm{~cm}^{2} / \mathrm{s}\left(D_{2}\right)$ and for particles with an average size of $1.9 \mu \mathrm{m}$ were $1.5 \cdot 10^{-11} \mathrm{~cm}^{2} / \mathrm{s}\left(D_{1}\right)$ and $2.0 \cdot 10^{-11} \mathrm{~cm}^{2} / \mathrm{s}\left(D_{2}\right)$. 


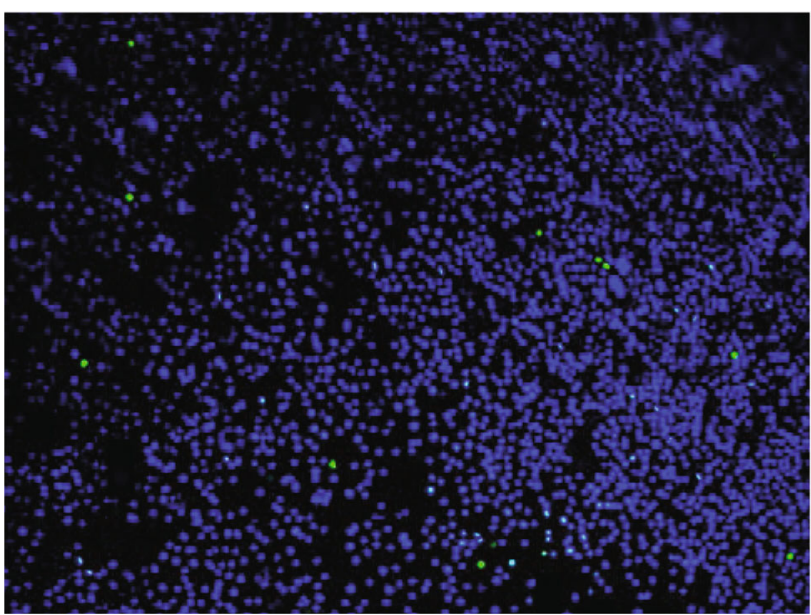

(a)

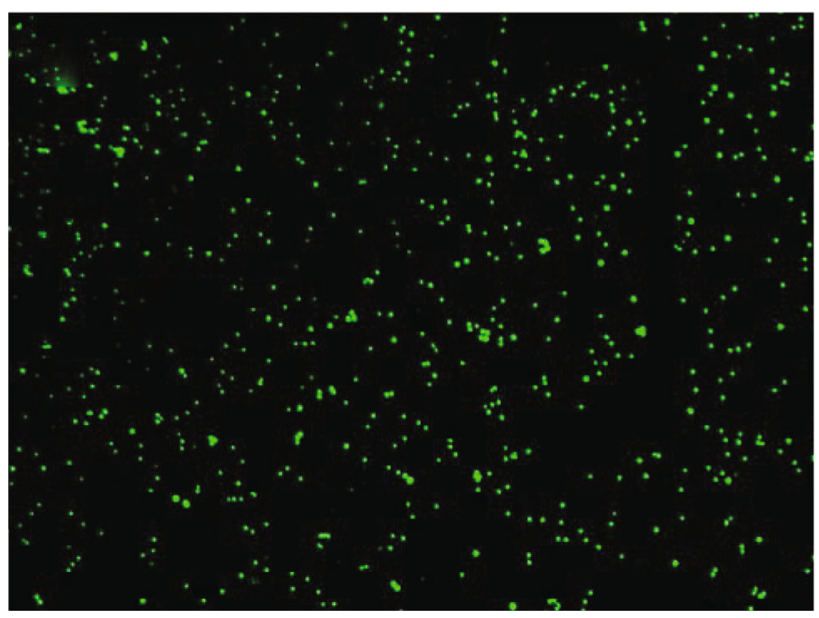

(c)

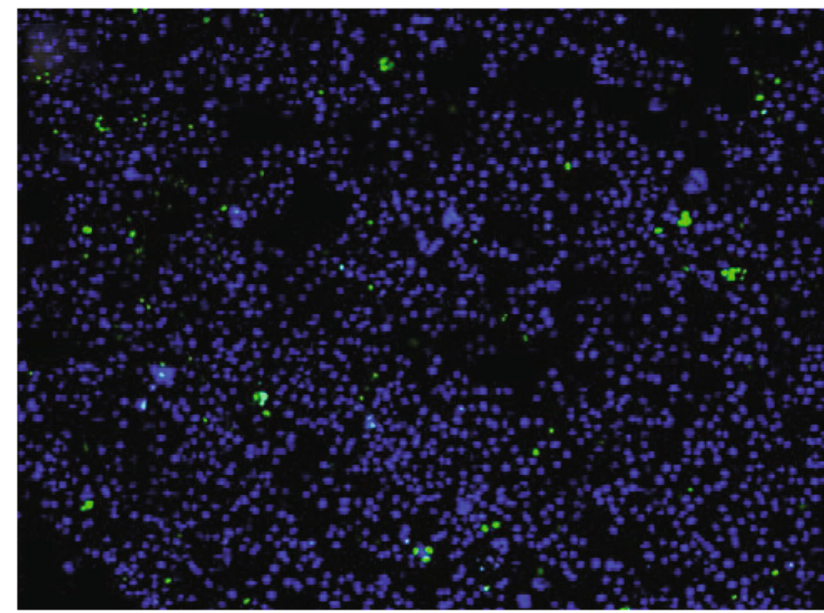

(b)

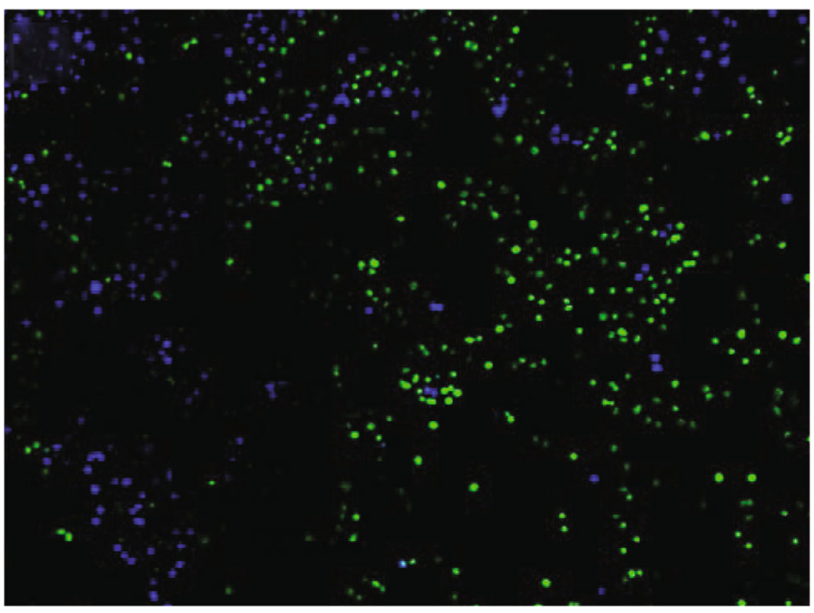

(d)

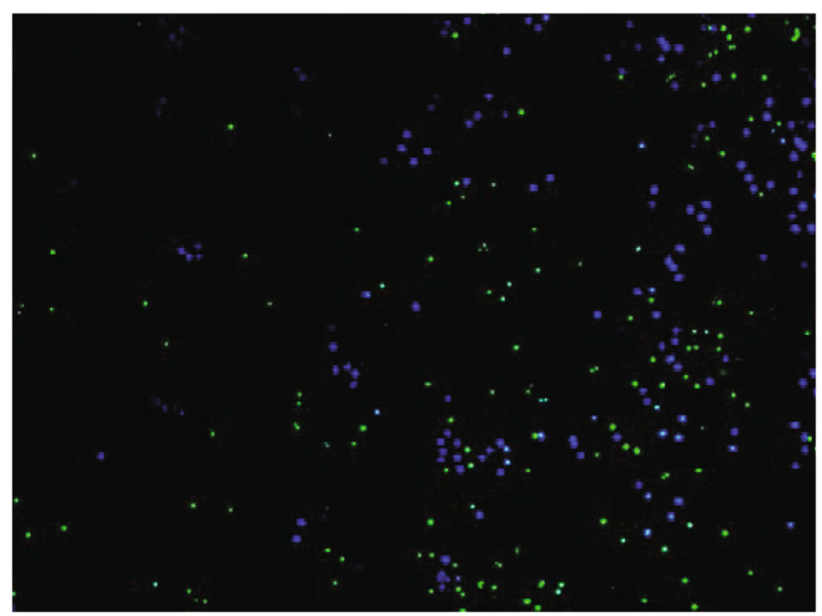

(e)

Figure 10: LIVE/DEAD assay: (a) $\mathrm{MP}_{\mathrm{EM}}$; (b) $\mathrm{MP}_{\mathrm{SD}}$; (c) $\mathrm{OZ}$ suspension; (d) OZ-MP $\mathrm{EM}_{\text {; }}$ (e) $\mathrm{OZ}-\mathrm{MP}_{\mathrm{SD}}$. Blue= live cells; green = dead cells. 
OZ release profiles from OZ-F are presented in Figure 8.

During the first 24 hours, significant drug release was noted: $22 \%$ for OZ-F (0.008wt.\%), 29\% for OZ-F (0.016 wt.\%), and 33\% for OZ-F (0.024 wt.\%).

Depot systems based on OZ-containing PHBV films are active for at least 9 days during the observation period. The amount of released OZ reaches $60 \%$ of encapsulated, for OZF containing $70.5 \mu \mathrm{mol} \mathrm{g}^{-1}$ (0.024 wt.\%) of OZ, $49 \%$ for OZ-F containing $47 \mu \mathrm{mol} \mathrm{g}^{-1}(0.016 \mathrm{wt} . \%)$ of OZ, and $40 \%$ for OZF containing $23.5 \mu \mathrm{mol} \mathrm{g}^{-1}(0.008 \mathrm{wt} . \%)$ of OZ.

The undoubted advantage of PHAs-based depot systems is the long period of their biological activity. These systems are active for several weeks and probably even months [69, 70], according to the dynamics of PHA degradation temps, which will be especially important in agriculture, for use in soils and in fields, during germination periods.

3.3. In Vitro Cytotoxicity. During the cultivation of HeLa in the presence of OZ-containing samples, it was noted that all depot systems inhibit cell growth and proliferation. The cytotoxicity directly depends on the concentration of OZ. Free OZ, suspended in water, showed pronounced cytotoxicity against HeLa cells.

The presence of $\mathrm{OZ}$ in PHA films significantly reduced cell viability (\%). A decrease in the number of viable cells (Table 3) was observed in the case of the film with the highest content of OZ $\left(70.5 \mu \mathrm{mol} \mathrm{g}^{-1}\right)$, when only $2 \%$ of viable cells were noted.

$\mathrm{OZ}-\mathrm{MP}_{\mathrm{EM}}$ and $\mathrm{OZ}-\mathrm{MP}_{\mathrm{SD}}$ are slightly less active against HeLa cells (Table 4) apparently due to the not as close sample-cell contact as in the case of depot films.

The results of the LIVE/DEAD assay for films are presented in Figure 9.

The results of the LIVE/DEAD assay for microparticles and free $\mathrm{OZ}$ are presented in Figure 10.

As expected, it was noted that with the increase of $\mathrm{OZ}$ concentration in the film obtained, the number of viable cells significantly decreases, while the active concentrations of $\mathrm{OZ}$ are in the range of extremely low values from 47 to $70.5 \mu \mathrm{mol} \mathrm{g}^{-1}$. At a concentration of $23.5 \mu \mathrm{mol} \mathrm{g}{ }^{-1}$, the HeLa cell viability was approximately $20 \%$, which also confirms the high activity of the studied ozonide. Thus, the characteristics of the obtained OZ depot systems provide a basis for scaling up the study of the cytotoxic effects of OZ when it is encapsulated in the PHA matrix with the further development of anticancer, antiparasitic, antiviral, and other depot forms.

\section{Conclusion}

For the first time, two types of depot systems containing new organic peroxide-casting films and microparticles-based on microbial PHAs were synthesized. The addition of 1,2,4-trioxolane insignificantly changes the main physical characteristics of the PHA matrix: the decrease of melting point and crystallization temperature was noted. Microparticles loaded with OZ were obtained using two methods of micronization of polymer solutions: emulsification and spray drying, with the inclusion of OZ up to 9.7 mass \% and its complete sustained release in vitro during $312 \mathrm{~h}$. Casting films containing $0.008 \%, 0.016 \%$, and $0.024 \%$ of $\mathrm{OZ}$ caused a significant decrease in the number of living cells of the model cancer culture, which was the result of the high activity of the deposited compound. However, the limitations of the obtained systems are the difficulty in assessing the process of biodegradation of films and particles at this stage, as well as the relatively high sizes of microparticles. Reducing the particle size and increasing the zeta potential can potentially increase their aggregative stability in the studied media. Thus, depot systems containing 1,2,4-trioxolane based on biodegradable natural polymers have been developed.

\section{Data Availability}

All data included in this study are available upon request by contacting with the corresponding author.

\section{Conflicts of Interest}

There are no conflicts to declare.

\section{Acknowledgments}

This study was financially supported by the project "Agropreparations of the new generation: a strategy of construction and realization" (Agreement No 074-02-2018-328) in accordance with Resolution No 220 of the Government of the Russian Federation of April 9, 2010, "On measures designed to attract leading scientists to the Russian institutions of higher learning."

\section{References}

[1] Y. Tu, "The discovery of artemisinin (qinghaosu) and gifts from Chinese medicine," Nature Medicine, vol. 17, no. 10, pp. 1217-1220, 2011.

[2] N. J. White, T. T. Hien, and F. H. Nosten, "A Brief History of Qinghaosu," Trends in Parasitology, vol. 31, no. 12, pp. 607610, 2015.

[3] V. A. Vil', I. A. Yaremenko, A. I. Ilovaisky, and A. O. Terent'ev, "Synthetic Strategies for Peroxide Ring Construction in Artemisinin," Molecules, vol. 22, no. 1, p. 117, 2017.

[4] L. C. Fisher and M. Blackie, "Tetraoxanes as Antimalarials: Harnessing the Endoperoxide," Mini Reviews in Medicinal Chemistry, vol. 14, no. 2, pp. 123-135, 2014.

[5] P. Ghorai, P. H. Dussault, and C. Hu, "Synthesis of Spiro-bisperoxyketals," Organic Letters, vol. 10, no. 12, pp. 2401-2404, 2008.

[6] H. D. Hao, S. Wittlin, and Y. Wu, "Potent Antimalarial 1,2,4Trioxanes through Perhydrolysis of Epoxides," Chemistry - A European Journal, vol. 19, no. 23, pp. 7605-7619, 2013.

[7] B. A. Šolaja, N. Terzić, G. Pocsfalvi et al., "Mixed Steroidal 1,2,4,5-Tetraoxanes: Antimalarial and Antimycobacterial Activity," Journal of Medicinal Chemistry, vol. 45, no. 16, pp. 3331-3336, 2002.

[8] C. W. Jefford, "Synthetic Peroxides as Potent Antimalarials. News and Views," Current Topics in Medicinal Chemistry, vol. 12, no. 5, pp. 373-399, 2012. 
[9] X. Wang, Y. Dong, S. Wittlin et al., "Comparative Antimalarial Activities and ADME Profiles of Ozonides (1,2,4-trioxolanes) OZ277, OZ439, and Their 1,2-Dioxolane, 1,2,4-Trioxane, and 1,2,4,5-Tetraoxane Isosteres," Journal of Medicinal Chemistry, vol. 56, no. 6, pp. 2547-2555, 2013.

[10] M. B. Chaudhari, N. Mohanta, A. M. Pandey, M. Vandana, K. Karmodiya, and B. Gnanaprakasam, "Peroxidation of 2oxindole and barbituric acid derivatives under batch and continuous flow using an eco-friendly ethyl acetate solvent," Reaction Chemistry \& Engineering, vol. 4, no. 7, pp. 1277-1283, 2019.

[11] C. Giannangelo, F. J. I. Fowkes, J. A. Simpson, S. A. Charman, and D. J. Creek, "Ozonide Antimalarial Activity in the Context of Artemisinin-Resistant Malaria," Trends in Parasitology, vol. 35, no. 7, pp. 529-543, 2019.

[12] J. Xiao, Z. Sun, F. Kong, and F. Gao, "Current scenario of ferrocene-containing hybrids for antimalarial activity," European Journal of Medicinal Chemistry, vol. 185, article 111791, 2020.

[13] J. Boissier, J. Portela, V. Pradines, F. Coslédan, A. Robert, and B. Meunier, "Activity of trioxaquine PA1259 in mice infected by Schistosoma mansoni," Comptes Rendus Chimie, vol. 15, no. 1, pp. 75-78, 2012.

[14] K. Ingram, I. A. Yaremenko, I. B. Krylov, L. Hofer, A. O. Terent'ev, and J. Keiser, "Identification of Antischistosomal Leads by Evaluating Bridged 1,2,4,5-Tetraoxanes, Alphaperoxides, and Tricyclic Monoperoxides," Journal of Medicinal Chemistry, vol. 55, no. 20, pp. 8700-8711, 2012.

[15] J. Keiser, K. Ingram, M. Vargas et al., "In Vivo Activity of Aryl Ozonides against Schistosoma Species," Antimicrobial Agents and Chemotherapy, vol. 56, no. 2, pp. 1090-1092, 2012.

[16] J. Keiser, V. Veneziano, L. Rinaldi, L. Mezzino, U. Duthaler, and G. Cringoli, "Anthelmintic activity of artesunate against Fasciola hepatica in naturally infected sheep," Research in Veterinary Science, vol. 88, no. 1, pp. 107-110, 2010.

[17] T. Küster, N. Kriegel, B. Stadelmann et al., “Amino ozonides exhibit in vitro activity against Echinococcus multilocularis metacestodes," International Journal of Antimicrobial Agents, vol. 43, no. 1, pp. 40-46, 2014.

[18] V. Vil', I. Yaremenko, A. Ilovaisky, and A. Terent'ev, "Peroxides with Anthelmintic, Antiprotozoal, Fungicidal and Antiviral Bioactivity: Properties, Synthesis and Reactions," Molecules, vol. 22, no. 11, p. 1881, 2017.

[19] L. I. L. Cabral, S. Pomel, S. Cojean, P. S. M. Amado, P. M. Loiseau, and M. L. S. Cristiano, "Synthesis and Antileishmanial Activity of 1,2,4,5-Tetraoxanes against Leishmania donovani," Molecules, vol. 25, no. 3, p. 465, 2020.

[20] R. P. Abrams, W. L. Carroll, and K. A. Woerpel, "Five-Membered Ring Peroxide Selectively Initiates Ferroptosis in Cancer Cells," ACS Chemical Biology, vol. 11, no. 5, pp. 1305-1312, 2016.

[21] A. A. Alagbala, A. J. McRiner, K. Borstnik et al., "Biological Mechanisms of Action of Novel C-10 Non-Acetal Trioxane Dimers in Prostate Cancer Cell Lines," Journal of Medicinal Chemistry, vol. 49, no. 26, pp. 7836-7842, 2006.

[22] D. Chaturvedi, A. Goswami, P. Pratim Saikia, N. C. Barua, and P. G. Rao, "Artemisinin and its derivatives: a novel class of anti-malarial and anti-cancer agents," Chemical Society Reviews, vol. 39, no. 2, pp. 435-454, 2010.

[23] M. B. Chaudhari, S. Moorthy, S. Patil et al., "Iron-Catalyzed Batch/Continuous Flow C-H Functionalization Module for the Synthesis of Anticancer Peroxides," The Journal of Organic Chemistry, vol. 83, no. 3, pp. 1358-1368, 2018.

[24] H. H. Chen, H. J. Zhou, W. Q. Wang, and G. D. Wu, “Antimalarial dihydroartemisinin also inhibits angiogenesis," Cancer Chemotherapy and Pharmacology, vol. 53, no. 5, pp. 423432, 2004.

[25] P. Coghi, I. A. Yaremenko, P. Prommana et al., "Novel Peroxides as Promising Anticancer Agents with Unexpected Depressed Antimalarial Activity," ChemMedChem, vol. 13, no. 9, pp. 902-908, 2018.

[26] I. A. Yaremenko, M. A. Syroeshkin, D. O. Levitsky, F. Fleury, and A. O. Terent'ev, "Cyclic peroxides as promising anticancer agents: in vitro cytotoxicity study of synthetic ozonides and tetraoxanes on human prostate cancer cell lines," Medicinal Chemistry Research, vol. 26, no. 1, pp. 170-179, 2017.

[27] I. A. Yaremenko, P. Coghi, P. Prommana et al., "Synthetic Peroxides Promote Apoptosis of Cancer Cells by Inhibiting PGlycoprotein ABCB5," ChemMedChem, vol. 15, no. 13, pp. 1118-1127, 2020.

[28] A. Dwivedi, A. Mazumder, L. du Plessis, J. L. du Preez, R. K. Haynes, and J. du Plessis, "In vitro anti-cancer effects of artemisone nano-vesicular formulations on melanoma cells," Nanomedicine : Nanotechnology, Biology, and Medicine, vol. 11, no. 8, pp. 2041-2050, 2015.

[29] D. M. Rubush, M. A. Morges, B. J. Rose, D. H. Thamm, and T. Rovis, "An Asymmetric Synthesis of 1,2,4-Trioxane Anticancer Agents via Desymmetrization of Peroxyquinols through a Brønsted Acid Catalysis Cascade," Journal of the American Chemical Society, vol. 134, no. 33, pp. 1355413557, 2012.

[30] F. Gao, Z. Sun, F. Kong, and J. Xiao, "Artemisinin-derived hybrids and their anticancer activity," European Journal of Medicinal Chemistry, vol. 188, article 112044, 2020.

[31] V. A. Vil', I. A. Yaremenko, D. I. Fomenkov, D. O. Levitsky, F. Fleury, and A. O. Terent'ev, "Ion exchange resin-catalyzed synthesis of bridged tetraoxanes possessing in vitro cytotoxicity against HeLa cancer cells," Chemistry of Heterocyclic Compounds, vol. 56, no. 6, pp. 722-726, 2020.

[32] S. W. Chou, G. Marousek, S. Auerochs, T. Stamminger, J. Milbradt, and M. Marschall, "The unique antiviral activity of artesunate is broadly effective against human cytomegaloviruses including therapy-resistant mutants," Antiviral Research, vol. 92, no. 2, pp. 364-368, 2011.

[33] T. Efferth, M. R. Romero, D. G. Wolf, T. Stamminger, J. J. G. Marin, and M. Marschall, "The Antiviral Activities of Artemisinin and Artesunate," Clinical Infectious Diseases, vol. 47, no. 6, pp. 804-811, 2008.

[34] C. Reiter, T. Fröhlich, L. Gruber et al., "Highly potent artemisinin-derived dimers and trimers: Synthesis and evaluation of their antimalarial, antileukemia and antiviral activities," Bioorganic \& Medicinal Chemistry, vol. 23, no. 17, pp. 5452-5458, 2015.

[35] I. A. Yaremenko, M. Y. Syromyatnikov, P. S. Radulov et al., "Cyclic Synthetic Peroxides Inhibit Growth of Entomopathogenic Fungus Ascosphaera apis without Toxic Effect on Bumblebees," Molecules, vol. 25, no. 8, p. 1954, 2020.

[36] I. A. Yaremenko, P. S. Radulov, Y. Y. Belyakova et al., "Catalyst Development for the Synthesis of Ozonides and Tetraoxanes Under Heterogeneous Conditions: Disclosure of an Unprecedented Class of Fungicides for Agricultural Application," Chemistry - A European Journal, vol. 26, no. 21, pp. 47344751, 2020. 
[37] A. Rathi, "Ranbaxy launches new anti-malarial Synriam," Chemistry World, 2021, https://www.chemistryworld.com/ news/ranbaxy-launches-new-anti-malarial-synriam/4967 .article.

[38] A. K. Ghosh, H. Miller, K. Knox, M. Kundu, K. J. Henrickson, and R. Arav-Boger, "Inhibition of Human Coronaviruses by Antimalarial Peroxides," ACS Infectious Diseases, vol. 7, no. 7, pp. 1985-1995, 2021.

[39] P. C. Naha, V. Kanchan, and A. K. Panda, "Evaluation of Parenteral Depot Insulin Formulation using PLGA and PLA Microparticles," Journal of Biomaterials Applications, vol. 24, no. 4, pp. 309-325, 2009.

[40] K. Park, S. Skidmore, J. Hadar et al., "Injectable, long-acting PLGA formulations: Analyzing PLGA and understanding microparticle formation," Journal of Controlled Release, vol. 304, pp. 125-134, 2019.

[41] M. Shameem, H. Lee, and P. P. DeLuca, "A short-term (accelerated release) approach to evaluate peptide release from PLGA depot formulations," AAPS PharmSci, vol. 1, no. 3, pp. 1-6, 1999.

[42] D. B. Shenoy, R. J. D'Souza, S. B. Tiwari, and N. Udupa, "Potential Applications of Polymeric Microsphere Suspension as Subcutaneous Depot for Insulin," Drug Development and Industrial Pharmacy, vol. 29, no. 5, pp. 555-563, 2003.

[43] B. Yerragunta, B. Yerragunta, S. Jogala, and K. M. Chinnala, "Development of a novel 3-month drug releasing risperidone microspheres," Journal of Pharmacy \& Bioallied Sciences, vol. 7, no. 1, p. 37, 2015.

[44] E. Elmowafy, A. Abdal-Hay, A. Skouras, M. Tiboni, L. Casettari, and V. Guarino, "Polyhydroxyalkanoate (PHA): applications in drug delivery and tissue engineering," Expert Review of Medical Devices, vol. 16, no. 6, pp. 467-482, 2019.

[45] S. Evangeline and T. B. Sridharan, "Biosynthesis and statistical optimization of polyhydroxyalkanoate (PHA) produced by Bacillus cereus VIT-SSR1 and fabrication of biopolymer films for sustained drug release," International Journal of Biological Macromolecules, vol. 135, pp. 945-958, 2019.

[46] B. Andreessen, N. Taylor, and A. Steinbüchel, "Poly(3-Hydroxypropionate): a Promising Alternative to Fossil Fuel-Based Materials," Applied and Environmental Microbiology, vol. 80, no. 21, pp. 6574-6582, 2014.

[47] E. I. Shishatskaya and T. G. Volova, “A comparative investigation of biodegradable polyhydroxyalkanoate films as matrices for in vitro cell cultures," Journal of Materials Science. Materials in Medicine, vol. 15, no. 8, pp. 915-923, 2004.

[48] S. F. Williams, D. P. Martin, D. M. Horowitz, and O. P. Peoples, "PHA applications: addressing the price performance issue," International Journal of Biological Macromolecules, vol. 25, no. 1-3, pp. 111-121, 1999.

[49] M. Singh, P. Kumar, S. Ray, and V. C. Kalia, "Challenges and Opportunities for Customizing Polyhydroxyalkanoates," Indian Journal of Microbiology, vol. 55, no. 3, pp. 235-249, 2015.

[50] F. Wan, A. Bohr, M. J. Maltesen et al., "Critical Solvent Properties Affecting the Particle Formation Process and Characteristics of Celecoxib-Loaded PLGA Microparticles via SprayDrying," Pharmaceutical Research, vol. 30, no. 4, pp. 10651076, 2013.

[51] K. Perveen, F. Masood, and A. Hameed, "Preparation, characterization and evaluation of antibacterial properties of epirubicin loaded PHB and PHBV nanoparticles," International
Journal of Biological Macromolecules, vol. 144, pp. 259-266, 2020.

[52] A. M. Shershneva, A. Murueva, E. Nikolaeva, E. Shishatskaya, and T. Volova, "Novel spray-dried PHA microparticles for antitumor drug release," Drying Technology, vol. 36, no. 11, p. 1387, 2017.

[53] S. V. Prudnikova, A. N. Boyandin, G. S. Kalacheva, and A. J. Sinskey, "Degradable Polyhydroxyalkanoates as Herbicide Carriers," Journal of Polymers and the Environment, vol. 21, no. 3, pp. 675-682, 2013.

[54] M. Y. Want, M. Islamuddin, G. Chouhan, A. K. Dasgupta, A. P. Chattopadhyay, and F. Afrin, "A new approach for the delivery of artemisinin: Formulation, characterization, and ex-vivo antileishmanial studies," Journal of Colloid and Interface Science, vol. 432, pp. 258-269, 2014.

[55] I. Charlie-Silva, N. M. Feitosa, H. C. S. Fukushima et al., "Effects of nanocapsules of poly- $\varepsilon$-caprolactone containing artemisinin on zebrafish early-life stages and adults," Science of the Total Environment, vol. 756, p. 143851, 2021.

[56] J. B. Yameogo, A. Geze, L. Choisnard et al., "Self-assembled biotransesterified cyclodextrins as Artemisinin nanocarriers I: Formulation, lyoavailability and in vitro antimalarial activity assessment," European Journal of Pharmaceutics and Biopharmaceutics, vol. 80, no. 3, pp. 508-517, 2012.

[57] N. Cowan, I. A. Yaremenko, I. B. Krylov, A. O. Terent'ev, and J. Keiser, "Elucidation of the in vitro and in vivo activities of bridged 1,2,4-trioxolanes, bridged 1,2,4,5-tetraoxanes, tricyclic monoperoxides, silyl peroxides, and hydroxylamine derivatives against Schistosoma mansoni," Bioorganic \& Medicinal Chemistry, vol. 23, no. 16, pp. 5175-5181, 2015.

[58] A. De Vita, C. Liverani, R. Molinaro et al., "Lysyl oxidase engineered lipid nanovesicles for the treatment of triple negative breast cancer," Scientific Reports, vol. 11, no. 1, p. 5107, 2021.

[59] R. Molinaro, J. O. Martinez, A. Zinger et al., "Leukocyte-mimicking nanovesicles for effective doxorubicin delivery to treat breast cancer and melanoma," Biomaterials Science, vol. 8, no. 1, pp. 333-341, 2020.

[60] M. Merino, T. Lozano, N. Casares et al., "Dual activity of PDL1 targeted Doxorubicin immunoliposomes promoted an enhanced efficacy of the antitumor immune response in melanoma murine model," Journal of Nanbiotechnology, vol. 19, no. 1, p. 102, 2021.

[61] I. A. Yaremenko, G. . P. Gomes, P. S. Radulov et al., "OzoneFree Synthesis of Ozonides: Assembling Bicyclic Structures from 1,5-Diketones and Hydrogen Peroxide," The Journal of Organic Chemistry, vol. 83, no. 8, pp. 4402-4426, 2018.

[62] I. A. Yaremenko, V. A. Vil', D. V. Demchuk, and A. O. Terent'ev, "Rearrangements of organic peroxides and related processes," Beilstein Journal of Organic Chemistry, vol. 12, pp. 1647-1748, 2016.

[63] A. V. Murueva, A. M. Shershneva, K. V. Abanina, S. V. Prudnikova, and E. I. Shishatskaya, "Development and characterization of ceftriaxone-loaded P3HB-based microparticles for drug delivery," Drying Technology, vol. 37, no. 9, pp. 11311142, 2019.

[64] G. A. Senhorini, S. F. Zawadzki, P. V. Farago, S. M. W. Zanin, and F. A. Marques, "Microparticles of poly(hydroxybutyrateco-hydroxyvalerate) loaded with andiroba oil: Preparation and characterization," Materials Science and Engineering: C, vol. 32, no. 5, pp. 1121-1126, 2012. 
[65] J. Bidone, A. P. P. Melo, G. C. Bazzo et al., "Preparation and characterization of ibuprofen-loaded microspheres consisting of poly(3-hydroxybutyrate) and methoxy poly (ethylene glycol)-b-poly (D,L-lactide) blends or poly(3-hydroxybutyrate) and gelatin composites for controlled drug release," Materials Science and Engineering: C, vol. 29, no. 2, pp. 588-593, 2009.

[66] T. G. Volova, N. O. Zhila, O. N. Vinogradova et al., "Constructing herbicide metribuzin sustained-release formulations based on the natural polymer poly-3-hydroxybutyrate as a degradable matrix," Journal of Environmental Science and Health Part B, vol. 51, no. 2, pp. 113-125, 2016.

[67] Y. Fu and W. J. Kao, "Drug release kinetics and transport mechanisms of non-degradable and degradable polymeric delivery systems," Expert Opinion on Drug Delivery, vol. 7, no. 4, pp. 429-444, 2010.

[68] V. A. Livshits, A. P. Bonartsev, A. L. Iordanskii et al., "Microspheres based on poly(3-hydroxy)butyrate for prolonged drug release," Polymer Science Series B, vol. 51, no. 7-8, pp. 256-263, 2009.

[69] E. G. Kiselev, A. N. Boyandin, N. O. Zhila et al., "Constructing sustained-release herbicide formulations based on poly-3hydroxybutyrate and natural materials as a degradable matrix," Pest Management Science, vol. 76, no. 5, pp. 17721785, 2020.

[70] T. Volova, A. Shumilova, N. Zhila, A. Sukovatyi, E. Shishatskaya, and S. Thomas, "Efficacy of Slow-Release Formulations of Metribuzin and Tribenuron Methyl Herbicides for Controlling Weeds of Various Species in Wheat and Barley Stands," ACS Omega, vol. 5, no. 39, pp. 25135-25147, 2020. 